\title{
Aspectos biológicos de Coccidophilus citricola Brèthes, 1905 (Coleoptera: Coccinellidae)
}

\author{
Biological aspects of Coccidophilus citricola Brèthes, 1905 (Coleoptera: Coccinellidae)
}

\author{
Ricardo Adaime da Silva ${ }^{1}$ Antonio Carlos Busoli ${ }^{2}$ Norton Rodrigues Chagas Filho ${ }^{3}$
}

\section{RESUMO}

Os aspectos biológicos do predador Coccidophilus citricola foram estudados sob condições controladas (temperatura de $24 \pm 2{ }^{\circ} \mathrm{C}, 70 \pm 10 \%$ de UR e 12 horas de fotofase), utilizando como alimento a cochonilha Aspidiotus nerii. Os valores registrados para duração e viabilidade foram: período embrionário (9,54 dias e 78,33\%); 1o estádio larval (4,22 dias e 90,00\%); 2º estádio larval (2,85 dias e 100,00\%); 3e estádio larval (2,94 dias e 97,22\%); 4o estádio larval (3,22 dias e 94,29\%); fase larval (13,25 dias e 82,50\%); período de pré-pupa (2,57 dias e 100,00\%); fase de pupa (5,70 dias e 100,00\%); período larva-adulto $(21,53$ dias e $82,50 \%)$. Os períodos de préoviposição, oviposição e pós-oviposição duraram 8,20; 73,47 e 8,53 dias, respectivamente. O número de ovos/fêmea foi $114,13 e$ o número de ovos/fêmea/dia foi 1,54. A longevidade das fêmeas (90,20 dias) foi significativamente maior que a dos machos $(74,13$ dias).

Palavras-chave: predador, cochonilha, controle biológico.

\section{ABSTRACT}

The biological aspects of the predator Coccidophilus citricola were studied under controlled conditions (at $24 \pm 2^{\circ} \mathrm{C}, 70 \pm 10 \% \mathrm{RH}$ and 12 hours of photophase), fed on scale Aspidiotus nerii. The values registered to duration and viability were: embryonic period (9.54 days and $78.33 \%) ; 1^{\text {st }}$ larval stage (4.22 days and 90.00\%); $2^{\text {nd }}$ larval stage (2.85 days and $100.00 \%) ; 3^{\text {rd }}$ larval stage (2.94 days and 97.22\%); $4^{\text {th }}$ larval stage (3.22 days and 94.29\%); larval phase (13.25 days and $82.50 \%)$; pre-pupa period (2.57 days and $100.00 \%)$; pupal phase (5.70 days and $100.00 \%)$; larva-adult period (21.53 days and $82.50 \%)$. The pre-oviposition, oviposition and post-oviposition periods lasted 8.20, 73.47 and 8.53 days, respectively. The number of eggs/female was 114.13 and the number of eggs/female/day was 1.54. The longevity of females (90.20 days) was significantly higher than that of males (74.13 days).
Key words: predator, scale, biological control.

\section{INTRODUÇÃO}

A citricultura é uma atividade agrícola de grande importância para o Brasil, pois envolve a movimentação de altas cifras e gera inúmeros empregos (NEVES, 1992). Dentre as pragas dos citros, estão as cochonilhas-de-carapaça (Hemiptera: Diaspididae), cujos danos podem ser bastante severos, principalmente em função da sucção contínua de seiva de folhas, frutos e ramos; além da introdução de toxinas que podem ocasionar queda de folhas ou depreciar a qualidade dos frutos produzidos (BARTRA, 1974; NAKANO, 1991). São diversas as espécies de cochonilhas-de-carapaça que ocorrem em plantas citrícolas no Brasil, entre elas: Chrysomphalus aonidum, Lepidosaphis beckii, Parlatoria cinerea, Parlatoria pergandii, Parlatoria ziziphus, Pinnaspis aspidistrae, Selenaspidus articulatus e Unaspis citri.

O predador Coccidophilus citricola

Brèthes, 1905 (Coleoptera: Coccinellidae) é um dos principais inimigos naturais das cochonilhas-decarapaça na América do Sul (BOSQ, 1943; LIMA, 1948; GRAVENA, 1984). As larvas de C. citricola são diminutas, tendo cerca de $0,7 \mathrm{~mm}$ no $1^{\circ}$ estádio e $1,92 \mathrm{~mm}$ no $4^{\circ}$ estádio larval. Os adultos possuem corpo elíptico, fortemente convexo, tegumento negro e brilhante; machos e fêmeas medem 1,19 e 1,22mm de comprimento, respectivamente (SILVA, 2002). $\boldsymbol{C}$.

\footnotetext{
${ }^{1}$ Engenheiro Agrônomo, Doutor em Entomologia Agrícola, Pesquisador, Embrapa Amapá, Rodovia JK, Km 5, 68903-000, Macapá, AP. E-mail: adaime@cpafap.embrapa.br. Autor para correspondência.

${ }^{2}$ Engenheiro Agrônomo, Doutor em Entomologia, Professor Titular, Departamento de Fitossanidade, Faculdade de Ciências Agrárias e Veterinárias (FCAV), Universidade Estadual Paulista (UNESP), Via de Acesso Professor Paulo Donato Castellane, s/n, 14884-900, Jaboticabal, SP.

${ }^{3}$ Engenheiro Agrônomo, Doutorando em Entomologia Agrícola,, Departamento de Fitossanidade, FCAV, UNESP.
} 
citricola, tanto na fase larval quanto na adulta, preda ovos, ninfas e adultos de diaspidídeos, apresentando também o comportamento de depositar seus ovos sob as carapaças das cochonilhas (SILVA et al., 2001a; SILVA et al., 2002a).

Até o presente momento, $\boldsymbol{C}$. citricola foi pouco estudado, não havendo informações disponíveis sobre seus aspectos reprodutivos. Os trabalhos existentes limitam-se às fases imaturas do predador e estimativas da longevidade dos adultos. Na tentativa de preencher essa lacuna, foi realizado este trabalho com o objetivo de estudar os aspectos biológicos de C. citricola em condições de laboratório.

\section{MATERIAL E MÉTODOS}

O trabalho foi realizado nos Laboratórios de Bioecologia de Coccinelídeos e de Diaspidídeos, do Departamento de Fitossanidade da Faculdade de Ciências Agrárias e Veterinárias da Universidade Estadual Paulista, em Jaboticabal, SP, sob condições controladas de temperatura $\left(24 \pm 2^{\circ} \mathrm{C}\right)$, umidade relativa do $\operatorname{ar}(70 \pm 10 \%)$ e fotofase (12 horas).

\section{Criação massal de $A$. nerii}

Uma linhagem uniparental da cochonilha A. nerii, proveniente da Flórida, Estados Unidos, foi criada sobre abóboras híbridas japonesas "Cabotiá" (Cucurbita moschata x Cucurbita maxima var. tetsukabuto), dispostas em estantes de aço. Os procedimentos utilizados foram semelhantes aos descritos por ROSE (1990), que consistem em dispor abóboras matrizes infestadas pela cochonilha na prateleira superior da estante e, nas prateleiras inferiores, são dispostas as abóboras a serem colonizadas. A colonização ocorre por ninfas de $1^{\circ}$ estádio, móveis, que ao caminharem pela abóbora à procura de um local para sua fixação e alimentação, caem por gravidade sobre as abóboras das prateleiras inferiores, passando a colonizá-las.

Foram utilizadas abóboras com diâmetro médio de $15 \mathrm{~cm}$, casca com leves reentrâncias, sem ferimentos e com pedúnculo de, no mínimo, $2 \mathrm{~cm}$. As abóboras foram lavadas com água e sabão, com o auxílio de uma esponja, e posteriormente mergulhadas em solução de hipoclorito de sódio $(0,25 \%)$ por um minuto. Após secarem naturalmente, foram dispostas na estante, de acordo com a demanda por cochonilhas.

\section{Criação massal de $\boldsymbol{C}$. citricola}

Foram coletados cerca de 300 adultos em um pomar citrícola do município de Jaboticabal, SP, e levados ao laboratório. Alguns exemplares foram enviados à taxonomista para confirmar a identificação. Os coccinelídeos foram acondicionados em recipientes de plástico $(18 \times 18 \times 25 \mathrm{~cm})$, cuja tampa continha uma abertura coberta com "voil". Em cada recipiente foi colocada uma abóbora colonizada por A. nerii e cerca de 100 coccinelídeos adultos. Em intervalos regulares de 30 dias, os adultos foram transferidos para outras abóboras colonizadas por $\boldsymbol{A}$. nerii.

\section{Aspectos biológicos de $C$. citricola}

Da criação massal, foram coletadas diversas fêmeas com aproximadamente 30 dias de idade, sendo distribuídas individualmente em "arenas de oviposição”, desenvolvidas por SILVA et al. (2002b). Tais arenas, construídas com frascos de filme fotográfico, foram fixadas com alfinetes nas abóboras colonizadas por adultos de A. nerii. Diariamente, as arenas foram removidas e os coccinelídeos transferidos para outras arenas. Sob estereoscópio, foram levantadas as carapaças das cochonilhas, com auxílio de agulhas histológicas e pincéis, à procura de ovos dos coccinelídeos.

Foram separados 60 ovos, dispostos em placas de Petri com tampa, sobre papel de filtro umedecido com água destilada. Para registrar a eclosão das larvas e a viabilidade dos ovos, foram realizadas duas avaliações diárias.

Com o auxílio de um pincel de cerda única, foi transferida uma larva de 1o estádio de $\boldsymbol{C}$. citricola, recém-eclodida, para cada "arena de criação", constituída por uma área de aproximadamente $7 \mathrm{~cm}^{2}$, demarcada com cola "stick" sobre a superfície da abóbora. Foram feitas 40 repetições, sendo que cada arena continha quantidade suficiente de cochonilhas (ninfas de $2^{\circ}$ estádio) para que a larva do predador se alimentasse até tornar-se pré-pupa, de acordo com SILVA et al. (2001b). Foram realizadas duas avaliações diárias para registrar a duração dos estádios larvais, da fase larval, do período de pré-pupa, da fase de pupa e do período larva-adulto.

Foram formados 15 casais de adultos recém-emergidos, acondicionados nas arenas de oviposição. A cada 24 horas, foram realizadas avaliações à procura de ovos, da forma já descrita, até a morte de todos os insetos. Quando um macho morria e a respectiva fêmea continuava viva, outro macho era inserido na arena. Para as fêmeas, foram calculados os períodos de pré-oviposição, oviposição e pósoviposição, número de ovos total e diário, além da longevidade. Para os machos, foi calculada a longevidade daqueles que formaram os casais originais. Os dados relativos à longevidade de fêmeas 
e machos foram submetidos à análise de variância, sendo as médias comparadas pelo Teste de Tukey a $5 \%$ de probabilidade. Ao acaso, foi cronometrada a duração de 10 cópulas.

Foi adotado o delineamento inteiramente casualizado, sendo que os ovos, larvas, pré-pupas, pupas ou adultos compunham, individualmente, as repetições.

\section{RESULTADOS E DISCUSSÃO}

\section{Fases imaturas}

O período embrionário foi de $9,54 \pm 0,16$ dias e a viabilidade dos ovos foi de 78,33\%, valores semelhantes aos registrados por outros autores para a mesma espécie de predador. ALMEIDA (1990) registrou período embrionário de 8,14 dias e viabilidade de $75,38 \%$, sob temperatura média de $31,15^{\circ} \mathrm{C}$ e umidade relativa de $68,85 \%$. SANTOS (1995) e DOMENICI (1998) obtiveram 7,9 e 7,8 dias para o período embrionário e $77,6 \%$ e $78,1 \%$ para a viabilidade dos ovos, respectivamente, sob temperatura de $25 \pm 2^{\circ} \mathrm{C}$, umidade relativa de $65 \pm 2 \%$ e 12 horas de fotofase.

Os quatro estádios larvais de $\boldsymbol{C}$. citricola tiveram duração de 4,22; 2,85; 2,94 e 3,22 dias, totalizando uma fase larval de 13,25 dias (Tabela 1). O período de pré-pupa, a fase de pupa e o período larva-adulto duraram 2,57; 5,70 e 21,53 dias, respectivamente (Tabela 1). Resultados bastante semelhantes foram registrados por ALMEIDA (1990), alimentando o predador com Diaspis echinocacti, e por SANTOS (1995) e DOMENICI (1998), utilizando A. nerii como presa. Foram observados altos valores de viabilidade para $\boldsymbol{C}$. citricola (Tabela 1), não destoando dos obtidos por ALMEIDA (1990), SANTOS (1995) e DOMENICI (1998).

No final do 4ํestádio, as larvas agrupamse no pedúnculo ou em reentrâncias da superfície da abóbora, fixam-se ao substrato com a extremidade do abdome e assumem uma posição encurvada, caracterizando o período de pré-pupa. Em condições de campo, SANTOS (1995) verificou que as larvas procuram a face abaxial das folhas de citros para empupar.

\section{Fase adulta}

O número de fêmeas e machos emergidos foi de 18 e 15, caracterizando uma proporção sexual de 1 fêmea:0,83 macho. Esta proporção obtida é muito semelhante às registradas por ALMEIDA (1990), de 1 fêmea:0,92 macho, e por SANTOS (1995), de 1 fêmea:0,82 macho.

Os períodos de pré-oviposição, oviposição e pós-oviposição duraram 8,20; 73,47 e 8,53 dias, respectivamente (Tabela 2). As cópulas tiveram duração média de 18,6 minutos e iniciaram-se a partir do terceiro ou do quarto dia após a emergência dos insetos, permanecendo até os últimos dias de vida dos mesmos, corroborando as afirmações de HONEK (1996).

O número médio de ovos produzidos por fêmea foi 114,13, com média de 1,54 ovo/dia durante o período de oviposição (Tabela 2). O número médio de ovos/fêmea/dia oscilou bastante durante a vida da fêmea, havendo um grande pico aos 56 dias após a emergência (4,21 ovos) (Figura 1).

Dos 1712 ovos de $\boldsymbol{C}$. citricola coletados durante o presente trabalho, 99,3\% foram depositados sob as carapaças de $\boldsymbol{A}$. nerii, cujo corpo já havia sido

Tabela 1 - Duração e viabilidade dos estádios larvais, da fase larval, do período de pré-pupa, da fase de pupa e do período larva-adulto de $\boldsymbol{C}$. citricola, tendo como presa A. nerii. Temperatura de $24^{\circ} \mathrm{C}$, UR de $70 \pm 10 \%$ e fotofase de 12 horas. Jaboticabal, SP, 2001.

\begin{tabular}{|c|c|c|c|}
\hline \multirow{2}{*}{ Estádio/Fase/Período } & \multicolumn{2}{|c|}{ Duração (dias) } & \multirow{2}{*}{ Viabilidade (\%) } \\
\hline & $\bar{x} \pm \mathrm{EP}^{1}$ & Amplitude & \\
\hline $1^{\circ}$ e estádio & $4,22 \pm 0,14$ & $(2,67-7,04)$ & 90,00 \\
\hline $2^{\circ}$ estádio & $2,85 \pm 0,11$ & $(1,79-5,42)$ & 100,00 \\
\hline $3^{\circ}$ estádio & $2,94 \pm 0,08$ & $(2,13-3,98)$ & 97,22 \\
\hline 4º estádio & $3,22 \pm 0,14$ & $(2,02-5,08)$ & 94,29 \\
\hline Fase larva & $13,25 \pm 0,19$ & $(11,34-15,34)$ & 82,50 \\
\hline Pré-pupa & $2,57 \pm 0,10$ & $(1,75-3,92)$ & 100,00 \\
\hline Pupa & $5,70 \pm 0,10$ & $(4,75-7,08)$ & 100,00 \\
\hline Larva-adulto & $21,53 \pm 0,23$ & $(18,51-24,21)$ & 82,50 \\
\hline
\end{tabular}

${ }^{1}$ Média \pm erro padrão. 
Tabela 2 - Duração dos períodos de pré-oviposição, oviposição e pós-oviposição; número de ovos/fêmea e número de ovos/fêmea/dia de $\boldsymbol{C}$. citricola, tendo como presa $\boldsymbol{A}$. nerii. Temperatura de $24^{\circ} \mathrm{C}$, UR de $70 \pm 10 \%$ e fotofase de 12 horas. Jaboticabal, SP, 2001.

\begin{tabular}{lcc}
\hline \multirow{2}{*}{ Período } & \multicolumn{2}{c}{ Duração (dias) } \\
\cline { 2 - 3 } & $\bar{x} \pm \mathrm{EP}^{1}$ & Amplitude \\
\hline Pré-oviposição & $\begin{array}{c}8,20 \pm 0,79 \\
(\mathrm{n}=15)\end{array}$ & $6-18$ \\
Oviposição & $\begin{array}{c}73,47 \pm 5,32 \\
(\mathrm{n}=15)\end{array}$ & $39-100$ \\
Pós-oviposição & $\begin{array}{c}8,53 \pm 1,76 \\
(\mathrm{n}=15)\end{array}$ & $1-27$ \\
\hline Ovos/fêmea & $\begin{array}{c}114,13 \pm 12,17 \\
(\mathrm{n}=15)\end{array}$ & $36-185$ \\
\hline Ovos/fêmea/dia & $\begin{array}{c}1,54 \pm 0,13 \\
(\mathrm{n}=15)\end{array}$ & $0,69-2,43$ \\
\hline
\end{tabular}

${ }^{1}$ Média \pm erro padrão.

parcial ou totalmente predado. Somente 12 ovos $(0,7 \%)$ foram depositados fora das carapaças, nesses casos sobre a superfície da abóbora ou sobre as bordas externas da carapaça. O fato de os ovos serem depositados em sua grande maioria sob as carapaças das cochonilhas demonstra que $\boldsymbol{C}$. citricola busca a proteção de sua prole. Dessa forma, a eclosão das larvas fica praticamente assegurada, por estarem menos expostas aos fatores meteorológicos (vento, raios solares, precipitação pluviométrica, etc.) e aos inimigos naturais. Além disso, a carapaça das cochonilhas pode impedir que produtos químicos aplicados no pomar entrem em contato com os ovos ou larvas.

O comportamento de depositar os ovos sob as carapaças das cochonilhas, também foi observado para outros coccinelídeos, por exemplo Lindorus lophantae, por MARÍN (1983); Zagloba beaumonti, por LIMA (1999); e para Pentilia egena, por GUERREIRO et al. (2001).

As fêmeas de $\boldsymbol{C}$. citricola viveram significativamente mais que os machos (Tabela 3). A longevidade média obtida no presente ensaio foi bastante superior às registradas por SANTOS (1995) e por DOMENICI (1998), de 57,0 e 59,7 dias, respectivamente. Isso ocorreu, provavelmente, em função de que, no presente estudo, os adultos de $\boldsymbol{C}$. citricola tiveram condições ótimas para o seu desenvolvimento, pois foram transferidos diariamente para novas arenas de oviposição contendo presas,

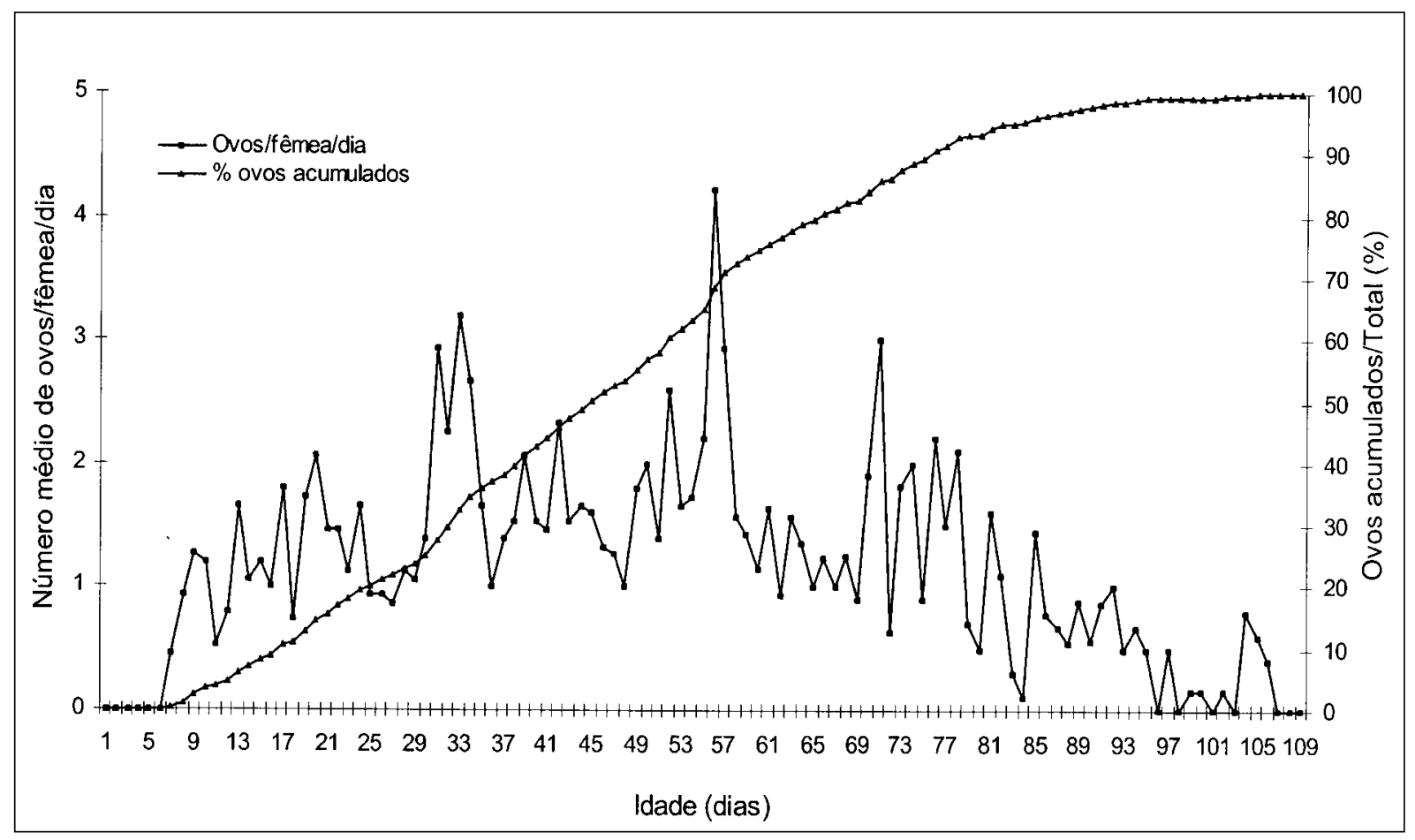

Figura 1 - Número médio de ovos depositados diariamente por fêmeas de $\boldsymbol{C}$. citricola e percentual de ovos acumulados, tendo como presa $\boldsymbol{A}$. nerii. Temperatura de $24^{\circ} \mathrm{C}$, UR de $70 \pm 10 \%$ e fotofase de 12 horas. Jaboticabal, SP, 2001.

Ciência Rural, v.34, n.3, mai-jun, 2004. 
Tabela 3 - Longevidade média de adultos de $\boldsymbol{C}$. citricola, tendo como presa $\boldsymbol{A}$. nerii. Temperatura de $24^{\circ} \mathrm{C}$, UR de 70 $\pm 10 \%$ e fotofase de 12 horas. Jaboticabal, SP, 2001 .

\begin{tabular}{lcc}
\hline \multirow{2}{*}{ Sexo } & \multicolumn{2}{c}{ Longevidade (dias) } \\
\cline { 2 - 3 } & $\bar{x} \pm \mathrm{EP}^{1}$ & Amplitude \\
\hline Fêmea & $\begin{array}{c}90,20 \pm 5,51 \mathrm{a}^{2} \\
(\mathrm{n}=15)\end{array}$ & $55-124$ \\
Macho & $\begin{array}{c}74,13 \pm 4,70 \mathrm{~b} \\
(\mathrm{n}=15)\end{array}$ & $46-103$ \\
\hline Média & $\begin{array}{c}82,17 \pm 3,86 \\
(\mathrm{n}=30)\end{array}$ \\
\hline
\end{tabular}

${ }^{1}$ Média \pm erro padrão

${ }^{2}$ Médias seguidas de letras distintas diferem significativamente entre si pelo teste de Tukey em nível de $5 \%$ de probabilidade de erro.

tendo sempre alimento disponível e mantendo excelente condições de assepsia.

\section{CONCLUSÃO}

C. citricola, quando criado em laboratório e alimentado com a cochonilha $\boldsymbol{A}$. nerii, completa seu ciclo e apresenta boa produção de ovos.

\section{AGRADECIMENTO}

À FAPESP (Fundação de Amparo à Pesquisa do Estado de São Paulo) pela bolsa de Doutorado concedida ao primeiro autor.

\section{REFERÊNCIAS BIBLIOGRÁFICAS}

ALMEIDA, R.P. Aspectos bioecológicos de predadores (Coleoptera: Coccinellidae) sobre a cochonilha da palma forrageira Diaspis echinocacti Bouché, 1833 (Homoptera: Diaspididae) em condições de laboratório. 1990. 138f. Dissertação (Mestrado em Fitossanidade) - Curso de Pós-graduação em Fitossanidade, Universidade Federal Rural de Pernambuco.

BARTRA, P.C.E. Biologia de Selenaspidus articulatus Morgan y sus principales controladores biológicos. Revista Peruana de Entomologia, Lima, v.17, n.1, p.60-68, 1974.

BOSQ, J.M. Coccinélideos útiles para la fruticultura tucumana. Revista Sociedade Entomologica Argentina, Buenos Aires, n.11, p.461-470, 1943.

DOMENICI, M.G. Aspectos biológicos e seletividade de acaricidas a Coccidophilus citricola Brèthes, 1905 (Coleoptera: Coccinellidae). 1998. 96f. Dissertação (Mestrado em Agronomia) - Curso de Pós-graduação em Agronomia, Universidade Estadual Paulista.
GRAVENA, S. Manejo integrado de pragas dos citros. Laranja, Cordeirópolis, v.5, p.323-361, 1984.

GUERREIRO, J.C.; SILVA, R.A.; BUSOLI, A.C. Comportamento de oviposição de Pentilia egena Mulsant, 1850 (Col.: Coccinellidae). In: CONGRESSO DE ECOLOGIA DO BRASIL, 5., 2001, Porto Alegre, RS. Resumos... Porto Alegre: UFRGS, 2001. p.16

HONEK, A. Life history and development. In: HODEK, I.; HONEK, A. Ecology of Coccinellidae. Dordrecht : Kluwer, 1996. Chapter 4, p.61-93.

LIMA, A.M. da C. Entomófagos sulamericanos (parasitos e predadores) de insetos nocivos a agricultura. Boletim Sociedade Brasileira de Agronomia, Rio de Janeiro, v.11, n.1, p.1-32, 1948.

LIMA, I.M.M. Ciclo de vida de Zagloba beaumonti Casey, 1899 (Coleoptera: Coccinellidae) como predador de Diaspis echinocacti (Bouché, 1833) (Hemiptera: Sternorrhyncha: Diaspididae): duração, sobrevivência e fertilidade em condições de laboratório. 1999. 175f. Tese (Doutorado em Ciências Biológicas) - Curso de Pós-graduação em Ciências Biológicas, Universidade Federal do Paraná.

MARÍN, R. Biología y capacidad de predación de Lindorus lophantae (Blais) (Col.: Coccinellidae) predator de Pinnaspis aspidistrae (Sing.) (Hom.: Diaspididae). Revista Peruana de Entomologia, Lima, v.26, n.1, p.63-66, 1983.

NAKANO, O. Insetos nocivos aos citros. In: RODRIGUEZ, O. et al. Citricultura brasileira. 2. ed. Campinas : Fundação Cargill, 1991. V.2, p.557-600.

NEVES, E.M. Citricultura brasileira: importância econômica e perspectivas. Laranja, Cordeirópolis, v.13, n.2, p.55-62, 1992.

ROSE, M. Rearing and mass rearing. In: ROSEN, D. Armored scale insects their biology, natural enemies and control. Jerusalém : Elseiver, 1990. p.357-365.

SANTOS, A.C. dos. Aspectos bioecológicos e seletividade de agroquímicos a Coccidophilus citricola Brèthes (Coleoptera: Coccinellidae). 1995. 91f. Dissertação (Mestrado em Agronomia) - Curso de Pós-graduação em Agronomia, Universidade Estadual Paulista.

SILVA, R.A. Aspectos bioecológicos e caracterização morfológica de Coccidophilus citricola Brèthes, 1905 (Coleoptera: Coccinellidae). 2002. 147f. Tese (Doutorado em Agronomia) - Curso de Pós-graduação em Agronomia, Universidade Estadual Paulista.

SILVA, R.A. et al. Preferência alimentar de adultos de Coccidophilus citricola Brèthes (Coleoptera: Coccinellidae) por diferentes estágios da cochonilha Aspidiotus nerii (Bouchè) (Hemiptera: Diaspididae). In: SIMPÓSIO BRASILEIRO DA AGROINDÚSTRIA, 1., 2001, Uberaba, MG. Anais... Uberaba: FAZU/FUNDAGRI, 2001a. 1 CD.

SILVA, R.A. et al. Eficiência de predação de Aspidiotus nerii (Bouchè) (Hemiptera: Diaspididae) por larvas de Coccidophilus citricola Brèthes (Coleoptera: Coccinellidae) em condições de laboratório. In: SIMPÓSIO BRASILEIRO DA AGROINDÚSTRIA, 1., 2001, Uberaba, MG. Anais... Uberaba: FAZU/FUNDAGRI, 2001b. $1 \mathrm{CD}$. 
SILVA, R.A.; CHAGAS-FILHO, N.R.; BUSOLI, A.C. Comportamento de oviposição de Coccidophilus citricola Brèthes, 1905 (Coleoptera: Coccinellidae). In: REUNIÃO ANUAL DA SOCIEDADE BRASILEIRA PARA O PROGRESSO DA CIÊNCIA, 54., 2002, Goiânia, GO. Resumos... Goiânia : SBPC/UFG, 2002a. 1 CD.
SILVA, R.A.; CHAGAS-FILHO, N.R.; BUSOLI, A.C. Técnica alternativa de contenção de coccinelídeos predadores de diaspidídeos para estudos bioecológicos. In: REUNIÃO ANUAL DA SOCIEDADE BRASILEIRA PARA O PROGRESSO DA CIÊNCIA, 54., 2002, Goiânia, GO. Resumos... Goiânia : SBPC/ UFG, 2002b. 1 CD. 